\title{
INDUCIBLE NITRIC OXIDE SYNTHASE EXPRESSION IN VASCULAR AND GLOMERULAR STRUCTURES OF HUMAN CHRONIC ALLOGRAFT NEPHROPATHY
}

\author{
PAOLA ROMAGNANI ${ }^{1}$, CINZIA PUPILli ${ }^{1 *}$, LAURA LASAGNI ${ }^{1}$, MARIA C. BACCARI $^{2}$, FRANCESCA BELLINI $^{1}$, ANDREA AMOROSI $^{3}$, \\ ELISABETTA BERTONI ${ }^{4}$ AND MARIO SERIO ${ }^{1}$ \\ ${ }^{1}$ Department of Physiopathology, Endocrinology Unit, University of Florence, Italy \\ ${ }^{2}$ Department of Physiology, University of Florence, Italy \\ ${ }^{3}$ Institute of Anatomic Pathology, University of Florence, Italy \\ ${ }^{4}$ Renal Unit, Transplantation Centre, Florence, Italy
}

\begin{abstract}
SUMMARY
Nitric oxide (NO) plays an important role in the cytotoxic mechanisms responsible for acute renal allograft rejection, where macrophages produce high levels of inducible nitric oxide synthase (iNOS). By contrast, both the source and the role of NO in chronic allograft nephropathy (CAN) are still unclear. In this study, the expression of iNOS mRNA and protein was assessed in the kidneys of patients with graft failure due to chronic rejection. As controls, kidney specimens were obtained from patients undergoing nephrectomies for primary renal tumours, and from patients suffering from IgA nephropathy or mesangial-proliferative glomerulonephritis. In normal kidneys, iNOS production was absent or limited to a low signal, while it was found only in the inflammatory infiltrate of kidneys affected by glomerulonephritis, as assessed by immunohistochemistry and in situ hybridization. In contrast, in CAN, iNOS protein was localized not only in inflammatory cells, but also in vascular, glomerular, and, more rarely, tubular structures. Accordingly, in situ hybridization localized iNOS mRNA in both macrophages and lymphocytes, as well as in vascular structures and glomeruli. Double immunostaining for iNOS and $a$-smooth muscle actin (a-SMA) or von Willebrand factor (vWf) revealed that smooth muscle cells were the main vascular source of iNOS, while both mesangial and inflammatory cells were immunostained at the glomerular level. These data demonstrate that macrophages and lymphocytes are not the only source of iNOS mRNA and protein in human CAN. Vascular smooth muscle and mesangial cells also synthesize iNOS, raising the question of heterogeneous regulation and function of iNOS in this disease. Copyright (C) 1999 John Wiley \& Sons, Ltd.
\end{abstract}

KEY WORDS-kidney; vascular smooth muscle cell; mesangial cell; iNOS; chronic rejection; allograft nephropathy

\section{INTRODUCTION}

Despite the increased success of allograft transplantation, the rate of long-term graft attrition has remained constant, with the half-life of a renal transplant being 7 years or more. ${ }^{1}$ The leading cause of late kidney allograft failure is chronic rejection. ${ }^{2}$ Although a role for both immunological and non-immunological factors has been suggested, ${ }^{3}$ neither the aetiology nor the pathophysiology of this phenomenon is fully understood. Several reports have hypothesized a role for nitric oxide (NO) as a pro-inflammatory molecule in various models of transplant rejection. ${ }^{4-6}$ Indeed, NO is a highly reactive radical produced by several cell types which is involved in different physiological processes, ${ }^{7}$ as well as in different diseases. ${ }^{4} \mathrm{NO}$ is derived from the conversion of L-arginine to L-citrulline under the activity of the enzyme nitric oxide synthase (NOS). There are three major isoforms of NOS: ${ }^{7}$ the neuronal form (nNOS); the endothelial form (eNOS), which produces the amounts of NO required for physiological functions; and the cytokine-inducible form (iNOS). iNOS is induced by a number of immunological stimuli, such as IFN- $\gamma$, TNF- $\alpha$, and LPS, and catalyses a high output of NO,

*Correspondence to: Cinzia Pupilli, MD, PhD, Dipartimento di Fisiopatologia Clinica, Unità di Endocrinologia, Università di Firenze, Viale Pieraccini 6, 50139 Firenze, Italy. E-mail: c.pupilli@dfc.unifi.it which can be cytotoxic. Recent reports have focused their attention on the role of iNOS in various models of acute allograft rejection; ${ }^{8}$ specific iNOS inhibitors ameliorate the clinical symptoms of acute rejection, ${ }^{9}$ preventing the cytotoxic effects exerted by macrophage and lymphocyte-derived iNOS. However, given that the kidney is a very important source of iNOS at the level of both epithelial and vascular structures, ${ }^{7}$ in this study we have investigated mRNA and protein iNOS expression and localization in chronic allograft nephropathy (CAN).

\section{MATERIALS AND METHODS}

\section{Tissues}

Renal tissue specimens were analysed from six patients (one male and five female, age range 21-59 years) who underwent nephrectomy for chronic transplant failure. All routine slides were examined and histologically scored according to the Banff classification criteria (three patients were graded as $\operatorname{cg} 3, \mathrm{ct} 3, \mathrm{ci} 3, \mathrm{cv} 3$; two as cg3, ct2, ci3, cv3; and one as cg3, ct2, ci3, cv2). ${ }^{10}$ A clinical diagnosis of chronic rejection was supported by the evidence of elevated serum creatinine, proteinuria, and hypertension. The possibility of recurrent disease was excluded. All of the patients were on chronic 

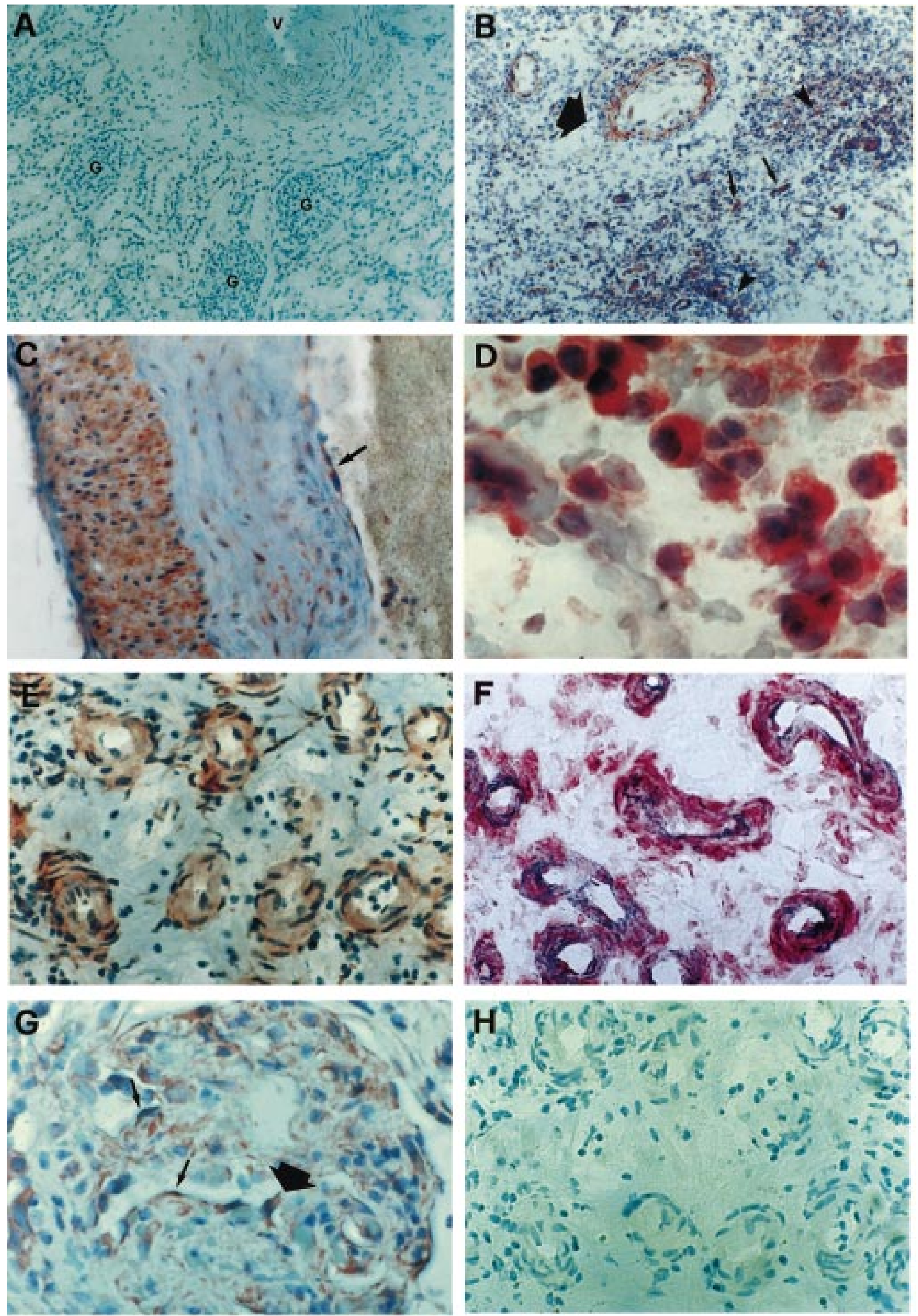
dialysis for chronic renal allograft rejection and during this period were treated with $1 \mathrm{mg} / \mathrm{kg}$ cyclosporin A (CsA) and $4 \mathrm{mg}$ of methylprednisolone; therapy was stopped immediately before nephrectomy, performed because of the occurrence of a slight degree of fever without sepsis, hypertension, and the need to stop the immunosuppressive therapy in order to prepare the patient for a second transplantation. Control tissues included (i) normal renal tissue obtained from five patients (two male and three female, age range 19-61 years) who underwent nephrectomy because of localized tumours and (ii) six renal biopsy specimens obtained from patients (two male and four female, age range $20-55$ years) affected by IgA nephropathy or mesangial-proliferative glomerulonephritis. Formalinfixed, paraffin-embedded, and frozen tissue specimens were available for both chronic allograft nephropathy cases and controls. Frozen CAN specimens were compared with frozen controls and paraffin CAN specimens with paraffin controls. The procedures followed in the study were in accordance with the ethical standards of the regional committee on human experimentation.

\section{Antibodies}

Anti-iNOS rabbit polyclonal antibody and its control blocking peptide were purchased from BIOMOL Research Laboratories, Inc. (DBA, Milan, Italy). The anti-iNOS antibody was directed against macrophage NOS c-terminal peptide (1131-1144) and reacted with iNOS protein in humans and mice. ${ }^{11}$ In order to identify smooth muscle cells and endothelial cells, a mouse monoclonal anti-human $a$-smooth muscle actin antibody ( $\alpha$-SMA; Sigma Immunochemicals, Milan, Italy) and a rabbit anti-human von Willebrand factor (vWf; DAKO, Denmark) were used, respectively.

\section{Immunohistochemistry}

Paraffin-embedded $(7 \mu \mathrm{m})$ or frozen sections $(10 \mu \mathrm{m})$ were cut. Frozen sections were fixed in 4 per cent paraformaldehyde and both types of sections were subsequently exposed to 3 per cent hydrogen peroxidemethanol solution to quench endogenous peroxidase activity. After a 30 min preincubation with normal goat serum (Vectastain Elite ABC kit; Vector Laboratories DBA, Milan, Italy), sections were layered for $30 \mathrm{~min}$ with anti-iNOS rabbit polyclonal antibody (1:1200), followed by biotinylated anti-rabbit $\mathrm{IgG}$ antibody and the avidin-biotin-peroxidase complex. ${ }^{12}$ 3-Amino-9ethylcarbazole (AEC; Sigma) was used as a peroxidase substrate. Sections were then counterstained with Gill's haematoxylin and mounted with Kaiser's glycerol gelatin (Merck, Germany). As negative controls, primary antibodies were omitted or replaced with rabbit serum or mouse ascites fluid. Furthermore, preadsorption using iNOS synthetic peptides completely abolished the staining.

\section{Double label immunohistochemistry}

iNOS and vWf or iNOS and $a$-SMA were co-localized on the same sections by double label immunohistochemistry, according to the method reported in ref. 12. Briefly, anti-iNOS antibody was applied first and AEC (red colour) was used as a peroxidase substrate. Sections were subsequently exposed to anti-vWf or anti- $\alpha$-SMA antibodies and Vector SG (bluish-grey colour) was used as a chromogen. No counterstain was applied.

\section{In situ hybridization}

In situ hybridization was performed according to a technique described elsewhere. ${ }^{13}$ Briefly, $10 \mu \mathrm{m}$ frozen sections were cut and fixed in 4 per cent paraformaldehyde. After a pre-hybridizaton treatment, sections were dehydrated and $30 \mu \mathrm{l}$ of hybridization solution containing $8 \times 10^{5}$ counts/min of ${ }^{35} \mathrm{~S}$-labelled human iNOS RNA probe was applied. Human inducible hepatocyte NOS RNA probes ${ }^{14}$ were synthesized from a $2 \cdot 1 \mathrm{~kb}$ fragment of hep-NOS cDNA cloned into the EcoRI/ BamHI site of pBluescript SK- (Stratagene). cDNA was digested with EcoRI and BamHI restriction enzymes to obtain a $2 \cdot 1 \mathrm{~kb}$ cDNA that was subcloned in PGEM-1 plasmid vector. Thereafter, sense and antisense RNA radiolabelled probes were synthesized using SP6 or T7 RNA polymerases as appropriate (Riboprobe Gemini System, Promega, Madison, WI, U.S.A.), in the presence of $a^{-35}$-thioUTP $(1300 \mathrm{mCi} / \mathrm{mmol}$; NEN-Du Pont, Paris, France). Hybridization was carried out at $52^{\circ} \mathrm{C}$ for $16 \mathrm{~h}$. After that, sections were washed and autoradiography was performed. ${ }^{13}$ The exposure time varied from 15 to 20 days. Sections were developed in D19, fixed in Kodak fixative, counterstained with haematoxylin-eosin-phloxine and mounted with Permount. Negative controls consisted of sections hybridized to a sense RNA probe.

Fig. 1-Detection by immunohistochemistry of iNOS protein (red colour) in the kidney from a patient with CAN. (A) Absence of iNOS immunostaining in the normal kidney from a patient who underwent nephrectomy for a localized renal tumour $(\mathrm{G}=\mathrm{glomerulus}$; $\mathrm{V}=\mathrm{vessel})$. (b) High levels of iNOS expression in the kidney of a patient affected by CAN. The smooth muscle layer of a large vessel (large arrow), some inflammatory cells (arrow-heads), and tubular structures (thin arrows) appear intensely positive. (C) High magnification of a vascular wall. Smooth muscle cells in the media and hyperplastic intima show intense iNOS immunostaining. Some endothelial cells are also positively stained (arrow). (D) High magnification of infiltrating inflammatory cells. (E) Vasa recta bundles showing immunoreactivity for iNOS. The image does not allow us to distinguish between smooth muscle, inflammatory, and endothelial cells. (F) Double label immunostaining for iNOS (red colour) and $a$-SMA (black colour). iNOS signal is localized over vascular cells showing $a$-SMA immunopositivity and over inflammatory interstitial cells. (G) Glomerular cells showing mesangial morphology (arrow-head) exhibit iNOS immunostaining. Immunoreactivity is also present in endothelial (arrows) and inflammatory cells. (H) Negative control: preadsorption using iNOS synthetic peptides completely abolished the staining in a section adjacent to E. $(A, B) \times 100$, reduced to 67 per cent in printing; $(\mathrm{C}, \mathrm{E}, \mathrm{F}, \mathrm{H}) \times 250$, reduced to 67 per cent in printing; $(\mathrm{G}) \times 400$, reduced to 67 per cent in printing; (D) $\times 1000$, reduced to 67 per cent in printing 


\section{Combined in situ hybridization and immunohistochemistry}

In situ hybridization for iNOS was performed as described above. After hybridization, sections were washed and immunostained for $a$-SMA or vWf, using AEC as a peroxidase substrate, and then autoradiography was performed. Sections were counterstained with Mayer's haematoxylin and mounted with Kaiser's glycerol gelatin.

\section{RESULTS}

\section{Localization of iNOS protein in human CAN}

In normal kidneys, iNOS was virtually undetectable by immunohistochemistry (Fig. 1A), while glomerulonephritis (GN) inflammatory cells were iNOS-positive (data not shown). In CAN, high immunoreactivity for iNOS was present not only in mononuclear leukocytes, but also in vascular structures (Fig. 1B and 1D). Interestingly, vascular positivity had a focal distribution and was often restricted to part of the media and neointima (Fig. 1C). In three out of six patients with CAN, endothelial cells from a few vessels and some glomeruli also stained positive for iNOS (Fig. 1C). Strong immunoreactivity was present over vasa recta bundles, but the nature of the cells staining positive for iNOS was uncertain (Fig. 1E). Double immunostaining for iNOS and $a$-SMA showed that smooth muscle cells were an important source of iNOS in addition to vesselsurrounding inflammatory cells (Fig. 1F). By contrast, iNOS protein co-localized with vWf in only a few cases.

Several glomerular cells showing mesangial morphology exhibited iNOS immunoreactivity (Fig. 1G), as confirmed by double label immunohistochemistry for iNOS and $a$-SMA. Occasionally, proximal and distal tubules together with medullary collecting ducts also showed iNOS reactivity (Fig. 1B). Preadsorption with a synthetic peptide corresponding to the peptide used as an immunogen completely abolished the staining (Fig. 1H).

\section{Localization of iNOS mRNA in human CAN}

A weak positive signal for iNOS mRNA was found over tubular, glomerular, and vascular structures in normal kidneys (Fig. 2A) and in the kidneys of patients suffering from GN, where infiltrating mononuclear cells exhibited a specific hybridization signal (data not shown). CAN specimens consistently showed iNOS mRNA expression over vascular structures, glomeruli, and the interstitium (Fig. 2B), while in sections hybridized with a sense RNA probe only a few scattered silver grains were observed (Fig. 2C). In CAN, the majority of positive cells were identifiable as infiltrating mononuclear cells (Fig. 2B and 2F), which often surrounded vasa recta bundles. In large and medium-sized vessels, inflammatory cells could easily be distinguished from smooth muscle cells (Fig. 2D), while in small vessels this distinction was less clear. A higher number of glomeruli showed intense signal all over the tuft, but discrimin- ation between infiltrating and glomerular cells was also impossible. To overcome this problem, both in situ hybridization for iNOS and immunohistochemistry for $a$-SMA or vWf were performed on the same section. Glomerular cells showing mesangial morphology and $a$-SMA positivity exhibited high levels of iNOS mRNA production (Fig. 2E). An intense mRNA signal over vascular cells showing $a$-SMA positivity and smooth muscle morphology was also observed, while iNOS mRNA rarely co-localized with vWf.

\section{DISCUSSION}

The results of this study demonstrate that iNOS is widely expressed in CAN at both the mRNA and protein level, as expected in the presence of an ongoing inflammatory reaction. Previous studies have indeed reported high iNOS production by inflammatory cells in rat models of acute renal allograft rejection and in human GN. ${ }^{8,15}$ Accordingly, large cells showing characteristic macrophage features, as well as other small mononuclear cells with lymphocyte morphology, stained positively for iNOS in the kidneys from patients with CAN. The relevant iNOS expression by mononuclear inflammatory cells in CAN can likely be explained by the presence of high levels of IFN- $\gamma$, IL-1, and TNF- $\alpha$ in this condition. ${ }^{16}$

The most relevant finding emerging from this study, however, was the demonstration that in CAN, iNOS distribution extended throughout vascular, glomerular, and, in some cases, tubular structures. Double staining experiments showed that apart from inflammatory cells, smooth muscle cells were the main source of iNOS expression. The capability of human vascular smooth muscle, endothelial, tubular, and mesangial cells to produce large amounts of iNOS has been clearly shown in several in vitro models. ${ }^{7}$ To our knowledge, however, this is the first in vivo study documenting iNOS synthesis by human vascular smooth muscle and mesangial cells.

The expression of iNOS by different cell types suggests that different mechanisms regulate iNOS activation in CAN and that immunological stimulation may not be the only reason for its induction. One possibility is that iNOS production results from chronic and repeated endothelial cell damage. Indeed, the expression of iNOS has been found in arterial smooth muscle in response to endothelial injury. ${ }^{17}$ Furthermore, the focal nature of vascular smooth muscle, mesangial, and tubular staining supports the possibility that local stimuli might be responsible for iNOS activation. Likewise, the discrepancy between high numbers of glomeruli showing iNOS mRNA expression and low numbers of glomeruli staining positive for the iNOS protein may reflect the possibility that local levels of cytokines do not consistently reach concentrations sufficient to allow the synthesis of the protein product, or that different cell subtypes react in a heterogeneous manner. The reason for the low levels of iNOS activation in endothelial cells is also unclear. A possible explanation may be the relevant endothelial damage, as demonstrated by the lack of vWf reactivity in many vessels in spite of an extended $\alpha$-SMA positivity 

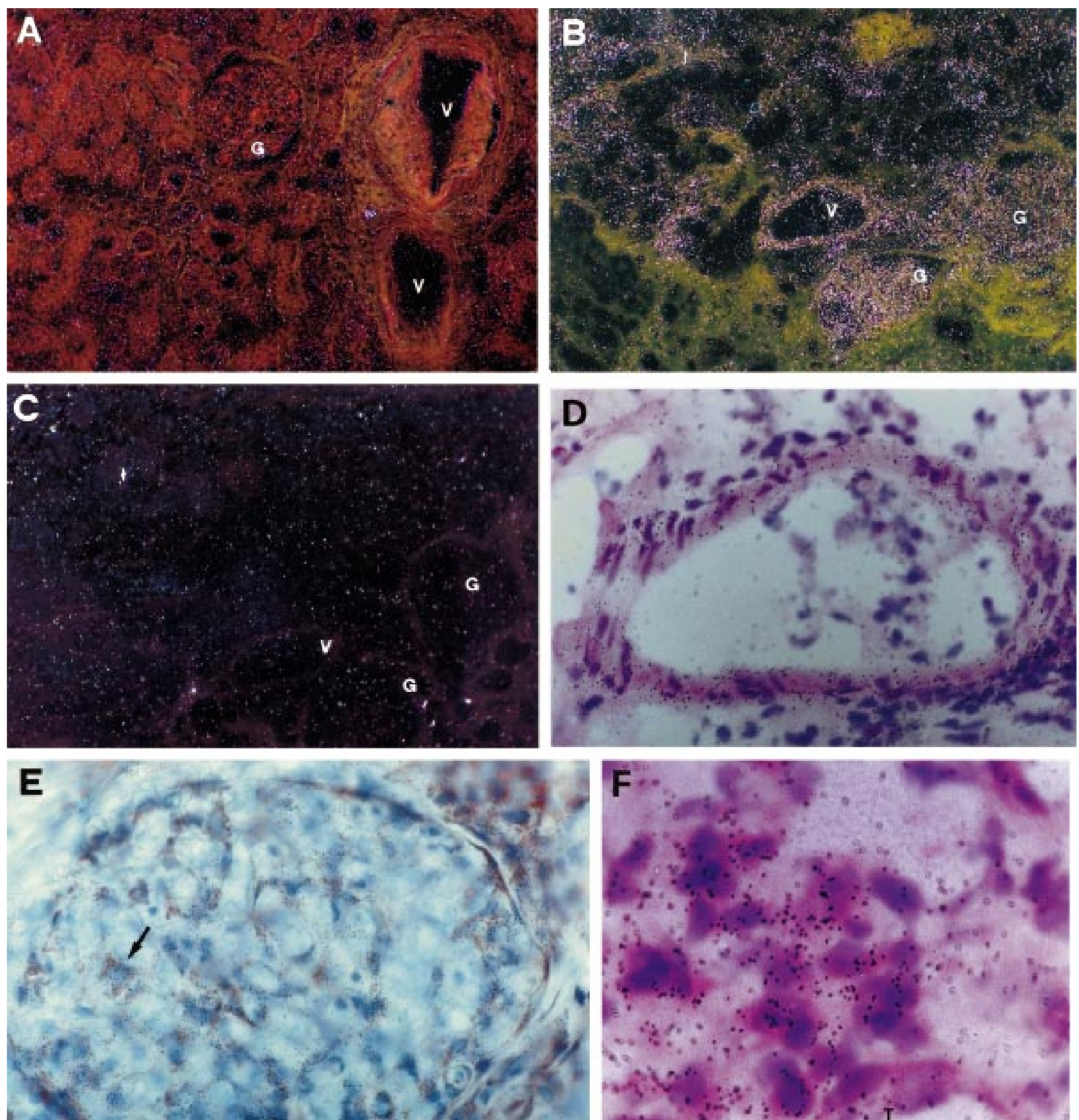

Fig. 2-Detection by in situ hybridization of iNOS mRNA in the kidney of a patient suffering from CAN. (A) Dark field of a normal human kidney hybridized with the iNOS antisense RNA probe. Positive signal (white grains) is weakly present over tubular, vascular, and glomerular structures $(\mathrm{G}=$ glomerulus; $\mathrm{V}=$ vessel). (B) Dark field of a tissue specimen of human CAN hybridized with the iNOS antisense RNA probe. A strong and diffuse signal is present over two glomeruli $(\mathrm{G})$, the wall of a vessel (V), and in many interstitial cells (I). (C) Dark field of a section adjacent to A, hybridized with a sense RNA probe. (D) High power magnification of a vessel hybridized with iNOS antisense RNA probe (black grains). Smooth muscle cells and inflammatory cells show positive iNOS signal. (E) Combined in situ hybridization (black grains) for iNOS and immunohistochemistry for $a$-SMA (red colour) in a glomerulus from a patient with CAN. Several cells showing mesangial morphology and $a$-SMA positivity (red colour, arrow) exhibit strong iNOS mRNA expression (black grains). (F) High levels of iNOS mRNA (black grains) over infiltrating mononuclear cells. (A, B, C) $\times 100$, reduced to 67 per cent in printing; (D, E) $\times 400$, reduced to 67 per cent in printing; $(\mathrm{F}) \times 1000$, reduced to 67 per cent in printing

caused by fibro-intimal hyperplasia. In addition, it is of note that all patients examined were treated with low dose CsA, which has been shown to act as a powerful inhibitor of iNOS induction in both vascular smooth muscle ${ }^{18}$ and mesangial cells. ${ }^{19}$ Thus, the possibility also exists that, at least in some cases, iNOS expression is underestimated. Furthermore, in order better to quantify the effective $\mathrm{NO}$ release in CAN patients, dosage of NO metabolites in peripheral blood could also be useful. 
The results of our study raise the question of the pathophysiological meaning of such widespread iNOS production in CAN. A recent report has demonstrated that rat aortic allografts show a significant increase in both iNOS mRNA and protein, as well as in intimal thickness. ${ }^{20}$ The inhibition of NO production with an iNOS inhibitor increased the intimal thickening, indicating that NO suppresses the development of allograft arteriosclerosis. Moreover, CsA inhibited iNOS expression in aortic allografts, with an increase in intimal thickening that was completely suppressed by iNOS gene transfer. All these data support the possibility that iNOS expression in kidneys of CAN does not simply reflect a pro-inflammatory and cytotoxic mechanism. Studies performed in LPS-injected rats have indeed shown that inhibition of NO leads to an increased expression of RANTES, a chemokine involved in the pathogenesis of CAN. ${ }^{16}$ Moreover, NO inhibits both TGF- $\beta$ and collagen synthesis in mesangial cells. ${ }^{21}$ Finally, NO may have an inhibitory effect on vascular smooth muscle cell proliferation. ${ }^{22}$ Thus, it is reasonable to suggest that iNOS production by vascular smooth muscle and mesangial cells in the kidneys of patients with CAN plays an important role in the inhibition of allograft arteriosclerosis and glomerulosclerosis. However, in order to substantiate this point, additional information is required on the regulatory mechanism underlying the activation of iNOS in different cell types.

\section{ACKNOWLEDGEMENTS}

We thank Mrs Nadia Misciglia for her excellent technical assistance and Dr Massimo Pinzani for the iNOS probe.

\section{REFERENCES}

1. Riesten CJ. In: Terasaki P, ed. Clinical Transplantation. Los Angeles: University of California, Los Angeles, Tissue Typing Laboratory, 1991; 225.

2. Dennis MJS, Foster MC, Ryan JJ, Burden RP, Morgan AG, Blamey RW The increasing importance of chronic rejection as a cause of renal allograft failure. Transplant Int 1989; 2: 214-217.

3. Lemström K, Koskinen P, Leyry P. Molecular mechanisms of chronic renal allograft rejection. Kidney Int 1995; 48 (Suppl 52): S2-S10.
4. Cook HT, Cattell V. Role of nitric oxide in immune-mediated diseases. Clin Sci 1996; 91: 375-384

5. Akyürek LM, Fellström BC, Yan Z, Hansson GK, Funa K, Larsson E. Inducible and endothelial nitric oxide synthase expression during development of transplant arteriosclerosis in rat aortic grafts. Am J Pathol 1996; 149: 1981-1990.

6. Russell ME, Wallace AF, Wyner LR, Newell JB, Karnovsky MJ. Upregulation and modulation of inducible nitric oxide synthase in rat cardiac allografts with chronic rejection and transplant arteriosclerosis. Circulation 1995; 92: 457-464.

7. Nathan C, Xie QW. Regulation of biosynthesis of nitric oxide. J Biol Chem 1994; 269: $13725-13728$.

8. Cattell V, Smith J, Jansen A, Riveros-Moreno V, Moncada S. Localization of inducible nitric oxide synthase in acute renal allograft rejection in the rat. Transplantation 1994; 58: 1399-1402.

9. Worrall NK, Lazenby WD, Misko TP, et al. Modulation of in vivo alloreactivity by inhibition of inducible nitric oxide synthase. J Exp Med 1995; 181: 63-70.

10. Solez K, Axelsen RA, Hallgrimur B, et al. International standardization of criteria for the histologic diagnosis of renal allograft rejection: the Banff working classification of kidney transplant pathology. Kidney Int 1993; 44: 411-422.

11. Pendino KJ, Meidhof TM, Heck DE, Laskin JD, Laskin DL. Inhibition of macrophages with gadolinium chloride abrogates ozone-induced pulmonary injury and inflammatory mediator production. Am J Respir Cell Mol Biol 1995; 13: 125-132.

12. Romagnani P, Annunziato F, Manetti R, et al. High CD30 ligand expression by epithelial cells and Hassal's corpuscles in the medulla of human thymus. Blood 1998; 91: 3323-3332.

13. Pupilli C, Romagnani P, Lasagni L, et al. Localization of endothelinconverting enzyme-1 in human kidney. Am J Physiol 1997; 273: F749-F756.

14. Geller DA, Lowenstein CJ, Shapiro RA, et al. Molecular cloning and expression of inducible nitric oxide synthase from human hepatocytes. Proc Natl Acad Sci USA 1993; 90: 3491-3495.

15. Kashem A, Masayukki E, Yano N, Yamauchi F, Nomoto Y, Sakai H. Expression of inducible-NOS in human glomerulonephrites: the possible source is infiltrating monocytes/macrophages. Kidney Int 1996; 50: 392-399.

16. Nadeau KC, Azuma H, Tilney NL. Seqential cytokine dynamics in chronic rejection of rat renal allografts: roles for cytokines RANTES and MCP-1. Proc Natl Acad Sci USA 1995; 92: 8729-8733.

17. Hansson GK, Geng Y, Holm J, Hardhammar P, Wennmalm A, Jennische E. Arterial smooth muscle cells express nitric oxide synthase in response to endothelial injury. J Exp Med 1994; 180: 733-738.

18. Marumo T, Nakaki T, Hishikawa K, Suzuki H, Kato R, Saruta T. Cyclosporin A inhibits nitric oxide synthase induction in vascular smooth muscle cells. Hypertension 1995; 25 (Part 2): 764-768.

19. Muhl H, Kunz D, Rob P, Pheilschifter J. Cyclosporin derivatives inhibit interleukin-1 beta induction of iNOS in renal mesangial cells. Eur $J$ Pharmacol 1993; 249: 95-100.

20. Shears LL II, Kawaharada N, Tzeng E, et al. Inducible nitric oxide synthase suppresses the development of allograft arteriosclerosis. J Clin Invest 1997; 100: 2035-2042.

21. Craven PA, Studer RK, Felder J, Phillips S, DeRubertis F. Nitric oxide inhibition of transforming growth factor- $\beta$ and collagen synthesis in mesangial cells. Diabetes 1997; 46: 671-681.

22. Garg UC, Hassid A. Nitric oxide-generating vasodilators and 8-bromocyclic guanosine monophosphate inhibit mitogenesis and proliferation of cultured rat vascular smooth muscle cells. J Clin Invest 1989; 83: 1774-1777. 